\title{
Questions About Sedation Protocols for Double-Balloon Enteroscopy
}

\author{
Dong-Hoon Yang \\ Department of Gastroenterology, Asan Medical Center, University of Ulsan College of Medicine, Seoul, Korea
}

The safety of endoscopic sedation is an important issue in gastrointestinal endoscopy. Elderly patients who require double-balloon enteroscopy (DBE) may be one of the highest risk groups for sedation-related complications due to the complexity and long procedure time of DBE as well as the frequent comorbidities present in elderly patients. In the original article titled "Double-Balloon Enteroscopy in Elderly Patients: Is It Safe and Useful?" in the latest issue of this journal, Choi et al. compared the safety of DBE between elderly ( $\geq 65$ years old) and non-elderly ( $<65$ years old) patients in Korea. ${ }^{1}$ According to their retrospective data, with the exception of an episode of transient hypoxia requiring intraprocedural oxygen supplementation, no sedation-related complications occurred in the course of 218 DBE procedures. Thus, the incidence of overall and clinically significant sedationrelated complications was $0.5 \%$ and $0 \%$, respectively. ${ }^{1}$

A recent large German retrospective study that included both young and elderly patients reported a similar incidence of sedation-related complications $(0.5 \%, 11 / 2,245$ DBE examinations). However, the definition of sedation-related complications was complications that necessitated intubation/noninvasive ventilation and early termination of the examination, ${ }^{2}$ and different from that in Choi's study. Other studies on the safety of DBE in the elderly reported that DBEs were performed under anesthesiologist-administered propofol-based sedation, ${ }^{3}$ monitored anesthesia care, ${ }^{4}$ or

Received December 3, 2014. Revised January 9, 2015.

Accepted January 9, 2015

Correspondence to Dong-Hoon Yang, Department of Gastroenterology, Asan Medical Center, University of Ulsan College of Medicine, 88 Olympic-ro

43-gil, Songpa-gu, Seoul 138-736, Korea. Tel: +82-2-3010-5809, Fax: +82-

2-3010-6517,E-mail:dhyang@amc.seoul.kr

Financial support: None. Conflict of interest: None. various levels of sedation ranging from conscious sedation to general anesthesia with participation of anesthesiologists. ${ }^{5}$ One of these studies reported only five sedation-related complications (2.3\%) in the elderly (3 hypoxia cases and 2 aspiration pneumonias), ${ }^{3}$ while none were reported in the other studies. ${ }^{4,5}$ It is likely that because these studies focused on the overall safety of DBE and not only on the safety of sedation for DBE procedures, their sedation protocols were not described in detail.

However, I think that it is very important to report not only the dose of sedatives, but also other sedation protocols, including pre-sedation patient assessment and periprocedural patient monitoring, in studies related to patient safety issues during any type of endoscopic procedure. Although little is known regarding the benefits of implementing a welldesigned sedation protocol, I hope the authors will share further details on their sedation protocols. For example, how they evaluated the DBE candidates before the procedure, how they monitored patients during/after the procedure, differences in endoscopic sedation protocols between DBE and other endoscopic procedures, and the need for a more individualized approach in the elderly.

\section{REFERENCES}

1. Choi DH, Jeon SR, Kim JO, et al. Double-balloon enteroscopy in elderly patients: is it safe and useful? Intest Res 2014;12:313319.

2. Möschler O, May A, Müller MK, Ell C; German DBE Study Group. Complications in and performance of double-balloon enteroscopy (DBE): results from a large prospective DBE database in Germany. Endoscopy 2011;43:484-489.

๑ Copyright 2015. Korean Association for the Study of Intestinal Diseases. All rights reserved.

This is an Open Access article distributed under the terms of the Creative Commons Attribution Non-Commercial License (http://creativecommons.org/licenses/by-nc/3.0)

which permits unrestricted non-commercial use, distribution, and reproduction in any medium, provided the original work is properly cited. 
3. Byeon JS, Mann NK, Jamil LH, Lo SK. Double balloon enteroscopy can be safely done in elderly patients with significant comorbidities. J Gastroenterol Hepatol 2012;27:1831-1836.

4. Hegde SR, Iffrig K, Li T, et al. Double-balloon enteroscopy in the elderly: safety, findings, and diagnostic and therapeutic success. Gastrointest Endosc 2010;71:983-989.
5. He Q, Zhang Q, Li JD, et al. Double balloon enteroscopy in the old: experience from China. World J Gastroenterol 2012; 18:2859-2866. 